\title{
The Reduction of Temperature on Opaque Wall by Arranging Floor - Covered Plant beside the Building
}

\author{
Patjaree Petchsalubsri, and Kua-anan Techato*
}

\begin{abstract}
This research aimed at using plant to be floor covered floor close to the building in order to reduce the heat accumulating and from the floor to the wall. By using the Pothos plant species (so called in various name e.g. Australian native monstera, centipede tongavine, devil's ivy, golden pothos, hunter's robe, ivy arum, money plant, silver vine, Solomon Islands ivy, and taro vine), the two testing rooms on the west side building of the Faculty of Environmental Management (Prince of Songkla University) where has the similar spaces and utility were used. The first testing room was designed to be the control study. The second room was used for the case study with floor - covered plant outside the building. The temperature of floor surface close to the building and the temperatures of wall outside the building of those two rooms were recorded by using the thermocouple type $\mathrm{K}$ and data logger. From the experiment, the Pothos can reduce the heat reflecting from the floor to the wall which can be seen from the different temperature 2-3 degree Celsius of the wall of two testing room. The different temperature is however supposed to be varied to the area of floorcovered plant which is the future work for this research.
\end{abstract}

Keywords - Pothos, Reduction of Temperature, Wall and Plant.

\section{INTRODUCTION}

$\mathrm{T}$ THE over-consumption of natural resources and energy effecting to global warming nowadays also to the unpredicted of climate change which can be seen from the average global temperature that continuously rising. By the time, human realized and tried to find a way to cope with it. One of many ways is using the air-conditioners but the side effect is going worse. The air-conditioning system is affecting the outside temperature in term of heat rejection. The airconditioning system also consumes a lot of energy, approximately $60-70 \%$, in building causing the emission of Carbon dioxide.

The solar radiation goes to the building directly and also the floor surface around the building which reflects to the building. This is the beginning of the study about reducing the heat reflecting from floor surface to the wall. The using of plant covering the building to block the solar radiation is called green wall and roof. Not only blocking the heat but also absorbing $\mathrm{CO}_{2}$ which is the major factor of global warming. In addition, the green makes the building better looks. However, there is yet a research about growing of plants that covered the concrete floor beside walls outside the building.

\section{LITERATURE REVIEW}

The using of plant to increase the green area can be either vertical green or green roof. It could be a part of the energy conservation. The vertical green can reduce the heat transfer to the building [1], [2]. The higher leave area index plant is normally can block the heat better than the lower leave area index plant [3], [4]. The side of the building is one factor to be concerned as the west side gain the highest solar radiation compared to others. [5].

\section{Methodology}

\section{A. Site}

The two testing rooms on the west side building of the Faculty of Environmental Management (Prince of Songkla University) were used. The first testing room was designed to be the control study. The second testing room was designed to be the room with plant as shown in Fig. 1.

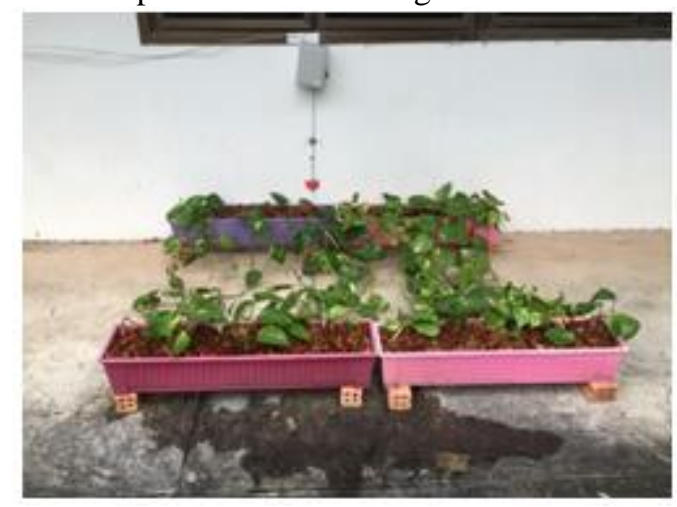

Fig. 1: The testing room with floor-covered plant

\section{B. Plant Material}

In this study, the Pothos plant species (so called in various name e.g. Australian native Monstera, Centipede Tongavine, Devil's Ivy, Golden Pothos, hunter's robe, ivy arum, money plant, silver vine, Solomon Islands ivy, and taro vine) had been used.
Patjaree Petchsalubsri, and Kua-anan Techato* are Faculty of Environmental Management, Prince of Songkla University 


\section{Instrument}

The temperatures on the wall were recorded by using the thermocouple type $\mathrm{K}$ and data logger.

\section{Data Collection}

Record the temperature on the wall both of testing rooms every hour from 8.00 am-5 pm then compare with other record from 1 Dec, 2015 to 3 Dec, 2015 (3days). This is the first set of data from testing. In the future, the testing will be done for one year

\section{RESULT AND DISCUSSION}

From the recorded temperature data, the average temperature of the wall of the controlled room from 8.00 17.00 hour during 1 st December 2015 to 3 December every hour were 2015 28.0, 29.0, 28.7, 29.3, 30.0, 31.0, 32.7, 31.5, 30.7, and 30.0 degree Celsius whereas the average temperatures of the case room were 27.0, 27.0, 27.0 27.5, 28.0, 27.8, 28.2, 28.8 29.2, and 29.3 degree Celsius as shown in Fig. 2.

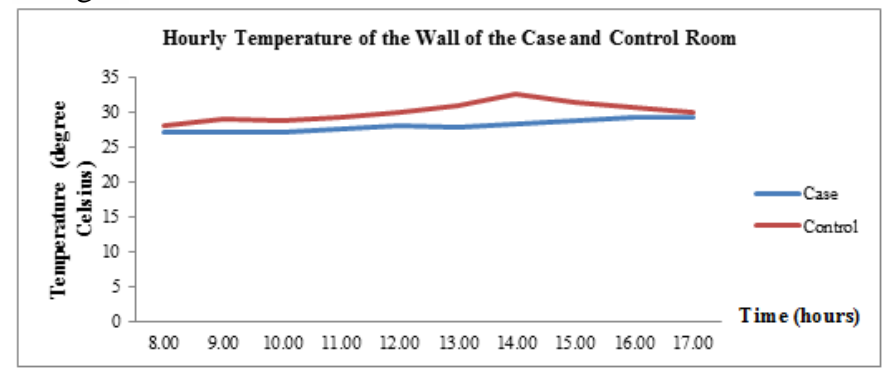

Fig. 2: The hourly temperature of the wall of the case and control room

\section{V.CONCLUSION}

The Pothos can reduce the heat reflecting from the floor to the wall which can be seen from the different temperature 2-3 degree Celsius of the wall of two testing rooms. The different temperature is however supposed to be varied to the area of floor-covered plant which is the future work for this research.

\section{ACKNOWLEDGMENT}

This Research was supported by Faculty of Environmental Management, Prince of Songkla University.

\section{REFERENCES}

[1] Nadia, S., Noureddine, S., Hichem, N. and Djamila, D. 2013. Experimental study of thermal performance and the contribution of plant-covered walls to the thermal behavior of building. Energy Procedia, 36: 995 - 1001 http://dx.doi.org/10.1016/j.egypro.2013.07.113

[2] Hien Wong, N., Yong Kwang Tan, A., Chen, Y., Sekar, K., Yok Tan, P., Chan, D., Chiang, K. and Chung Wong, N. 2010. Thermal evaluation of vertical greenery systems for building walls. Building and Environment, 45: 663-672 http://dx.doi.org/10.1016/j.buildenv.2009.08.005

[3] Berry, R., Livesley, S.J. and Aye, L. 2013. Tree canopy shade impacts on solar irradiance received by building walls and their surface temperature. Building and Environment, 69: 91-100 http://dx.doi.org/10.1016/j.buildenv.2013.07.009
[4] Nadia, S., Noureddine, S., Hichem, N. and Djamila, D. 2013. Experimental study of thermal performance and the contribution of plant-covered walls to the thermal behavior of building. Energy Procedia, 36: 995 - 1001 http://dx.doi.org/10.1016/j.egypro.2013.07.113

[5] Susorova, I., Azimi, P. and Stephens, B. 2014. The effects of climbing vegetation on the local microclimate, thermal performance, and air infiltration of four building facade orientations. Building and Environment, 76: 113-124.

http://dx.doi.org/10.1016/j.buildenv.2014.03.011 